\title{
The Acute Impact of Ingestion of Sourdough and Whole-Grain Breads on Blood Glucose, Insulin, and Incretins in Overweight and Obese Men
}

\author{
Anita Mofidi, Zachary M. Ferraro, Katherine A. Stewart, Hilary M. F. Tulk, \\ Lindsay E. Robinson, Alison M. Duncan, and Terry E. Graham \\ Department of Human Health and Nutritional Sciences, University of Guelph, Guelph, ON, Canada N1G 2W1 \\ Correspondence should be addressed to Terry E. Graham, terrygra@uoguelph.ca
}

Received 24 May 2011; Revised 20 September 2011; Accepted 17 November 2011

Academic Editor: Bernard Venn

Copyright () 2012 Anita Mofidi et al. This is an open access article distributed under the Creative Commons Attribution License, which permits unrestricted use, distribution, and reproduction in any medium, provided the original work is properly cited.

\begin{abstract}
Consumption of whole-grain and sourdough breads is associated with improved glucose homeostasis. We examined the impact of commercial breads on biomarkers of glucose homeostasis in subjects at risk for glucose intolerance. In a randomized, crossover study, overweight or obese males ingested 11-grain, sprouted-grain, 12-grain, sourdough, or white bread on different occasions, matched for available carbohydrate $(50 \mathrm{~g})$ in part $1(n=12)$ and bread mass $(107 \mathrm{~g})$ in part $2(n=11)$, and blood glucose, insulin and glucose-dependent insulinotropic polypeptide (GIP) and glucagon-like peptide-1 (GLP-1) were determined for $3 \mathrm{~h}$. In part 1, glucose response for sprouted-grain was lower than 11-grain, sourdough, and white breads. Insulin area under the curve (AUC) for sourdough and white was lower than 11-grain and sprouted-grain breads. GLP-1 response to sourdough was lower than all breads. In part 2, glucose and insulin AUC for sourdough was greater than 11-grain, sprouted-grain, and 12-grain breads. Sprouted-grain bread improved glycemia by lowering glucose response and increasing GLP-1 response. In overweight and obese men, the glycemic response to sprouted grain bread was reduced in both parts 1 and 2 while the other whole-grain test breads did not improve metabolic responses in the acute postprandial state.
\end{abstract}

\section{Introduction}

There is substantial interest in the role of dietary carbohydrate $(\mathrm{CHO})$ in preventing and managing type 2 diabetes (T2D) [1]. In North America, bread is the predominant CHO-containing food, and consumption of white bread is 5 times that of whole wheat, rye, and other dark breads [2]. Replacing white bread with whole-grain breads is often recommended to improve glycemic control [3]. Epidemiologic studies have reported inverse associations between whole-grain consumption and the risk of T2D and cardiovascular disease $[4-8]$, and clinical studies $[9,10]$ have reported beneficial effects of whole-grain consumption on the metabolic profile of subjects with impaired glycemic control. It has been suggested that the fiber content of whole-grain foods improves glucose/insulin metabolism by reducing the rate of $\mathrm{CHO}$ breakdown and absorption [1113].
The incretin hormones, glucose-dependent insulinotropic polypeptide (GIP), and glucagon-like peptide-1 (GLP1) are intimately involved in postprandial regulation of glucose homeostasis. It is estimated that approximately half of the postprandial insulin release in response to $\mathrm{CHO}$ ingestion is caused by these gut-derived hormones [1417]. Thus, the magnitude of the incretin response is vital to both the acute insulinemic and glycemic responses to $\mathrm{CHO}$ ingestion. However, our understanding of the impact of different types of $\mathrm{CHO}$ on the incretin response is still in its infancy.

Previously, we showed that ingestion of whole-wheat and whole-wheat barley breads did not result in attenuated insulin responses compared with white bread [18]. Furthermore, sourdough white bread resulted in lower glucose and GLP-1 responses for two subsequent meal periods [18]. In our previous work, ultrafinely grounded whole-wheat flour was used rather than whole-grain flour. In addition, in 
order to equalize the amount of available $\mathrm{CHO}(50 \mathrm{~g})$ across treatments, the bread mass consumed varied from 98 to $138 \mathrm{~g}$ resulting in higher energy, fat, protein, and fiber intake for the whole-wheat bread treatments [18]. Further study is needed to examine if bread mass influences the metabolic responses to bread.

The sprouting treatment of cereal grains is reported to decrease starch content and increase the content and availability of vitamins, minerals, and antioxidants [19]. One clinical study reported improved glycemia following consumption of pregerminated brown rice, compared to white rice, in healthy and type T2D subjects [20]. The metabolic effect of breads baked with sprouted wheat flour has not been extensively studied.

The present investigation had a distinct applied nature and tested the hypothesis that consumption of laboratoryprepared sourdough bread and commercially available whole-grain and sprouted-grain breads would result in lower metabolic responses compared with commercial, white bread in subjects who are at risk for glucose intolerance and T2D. This hypothesis was tested using 2 approaches including normalizing consumption of breads according to available $\mathrm{CHO}$ (part 1) and bread mass (part 2).

\section{Materials and Methods}

The study protocol was approved by the University of Guelph Human Research Ethics Board and each subject provided written informed consent. Subjects were recruited from the Guelph, Ontario area through advertisement in local newspapers. Subjects were overweight or obese males (body mass index (BMI): $25-35 \mathrm{~kg} / \mathrm{m}^{2}$ ), nonsmokers and had no history of gastrointestinal disease, gluten allergy, dyslipidemia, or diabetes. Subjects did not take medications (with the exception of antidepressants and/or antihypertensives) or natural health products. Potential subjects were screened for glucose intolerance and diabetes at a prestudy visit using a standard $2 \mathrm{~h}$ oral glucose tolerance test (OGTT) (Trutol Custom Laboratories Inc., Baltimore, MD). Subjects were excluded if they had impaired fasting plasma glucose $(>6.1 \mathrm{mmol} / \mathrm{L})$, impaired glucose tolerance $(>7.8 \mathrm{mmol} / \mathrm{L}$ at $2 \mathrm{~h})$, or impaired fasting insulin $(>90 \mathrm{pmol} / \mathrm{L})$.

2.1. General Protocol. Parts 1 and 2 of the investigation followed the same protocol, with the exception of the quantity of bread consumed. A single-blind, randomized crossover design was used with washout periods of at least 1 week between study days. Throughout the study, subjects were instructed to maintain their usual diet and lifestyle but were instructed to avoid alcohol, caffeine substances and strenuous physical activity $48 \mathrm{~h}$ prior to each study day and to report to the laboratory after an overnight (12h) fast. Dietary records were kept for three days prior to each study day and in the evening before each study day, subjects were instructed to consume a standardized meal, consisting of vegetable lasagne (President's Choice Blue Menu Reduced Fat Vegetable Lasagne) and a cereal bar (Kellogg's Nutri-Grain Cereal Bar).
TABle 1: Nutrient composition of the test breads delivering $50 \mathrm{~g}$ available $\mathrm{CHO}(\text { part } 1)^{1}$.

\begin{tabular}{|c|c|c|c|c|c|}
\hline & 11-grain & $\begin{array}{l}\text { Sprouted- } \\
\text { grain }\end{array}$ & Sourdough & 12-grain & White \\
\hline $\begin{array}{l}\text { Total } \\
\text { bread }(\mathrm{g})\end{array}$ & 151.0 & 157.2 & 107.3 & 122.2 & 110.3 \\
\hline $\begin{array}{l}\text { Available } \\
\text { CHO }(\mathrm{g})^{2}\end{array}$ & 50.0 & 50.0 & 50.0 & 50.0 & 50.0 \\
\hline $\begin{array}{l}\text { Energy } \\
\text { (kcal) }\end{array}$ & 320.2 & 336.4 & 277.9 & 317.8 & 273.7 \\
\hline Starch $(\mathrm{g})$ & 44.9 & 46.3 & 45.4 & 42.5 & 43.6 \\
\hline $\begin{array}{l}\text { Total } \\
\text { sugars (g) }\end{array}$ & 5.1 & 3.6 & 4.5 & 7.4 & 6.4 \\
\hline $\begin{array}{l}\text { Soluble } \\
\text { fiber (g) }\end{array}$ & 0.9 & 0.6 & 0.3 & 1.1 & 0.3 \\
\hline $\begin{array}{l}\text { Insoluble } \\
\text { fiber }(\mathrm{g})\end{array}$ & 11.9 & 11.4 & 4.9 & 9.9 & 4.6 \\
\hline $\begin{array}{l}\text { Dietary } \\
\text { fiber }(\mathrm{g})\end{array}$ & 12.8 & 12.1 & 5.2 & 11.0 & 4.9 \\
\hline Protein $(\mathrm{g})$ & 16.9 & 22.3 & 9.0 & 12.6 & 9.8 \\
\hline Fat $(\mathrm{g})$ & 3.1 & 2.9 & 4.3 & 5.2 & 3.6 \\
\hline
\end{tabular}

On each study day, a venous catheter was inserted into the forearm by a trained technician and kept patent for the duration of the experiment with a slow saline infusion. After collection of a fasting blood sample (time point $-15 \mathrm{~min}$ ), subjects consumed a serving of test bread with $250 \mathrm{~mL}$ of water within $15 \mathrm{~min}$. The laboratory clock started when subjects commenced eating the bread, and after $15 \mathrm{~min}$ (time point zero) the second blood sample was collected. Subsequently, blood samples were collected at 15, 30, 45, 60, $90,120,150$, and $180 \mathrm{~min}$.

\subsubsection{Part 1: Acute Postprandial Effect of Ingestion of Breads} Matched for Available Carbohydrate. Twelve overweight or obese males were recruited in part 1. The test breads were prepared to provide $50 \mathrm{~g}$ of available $\mathrm{CHO}$ which required portions of $151 \mathrm{~g}$ for 11-grain (whole-grain, with sourdough culture, Stone-mill Bakehouse Ltd., Scarborough, ON, Canada), $157 \mathrm{~g}$ of sprouted-grain (whole-grain, with sourdough culture, Stone-mill Bakehouse Ltd., Scarborough, ON, Canada), $107 \mathrm{~g}$ of sourdough white (as described previously [18] and baked at the Guelph Food Technology Centre at the University of Guelph), $122 \mathrm{~g}$ of 12-grain (whole-grain, Dempsters, Canada Bread Ltd., Brampton, ON, Canada), and $110 \mathrm{~g}$ of white bread (Wonder Bread, Weston Bakeries Ltd., Toronto, ON, Canada) (Table 1). Breads were sliced, decrusted and stored at $-20^{\circ} \mathrm{C}$ until consumption. Before consumption, the bread slices were thawed in a microwave oven for $15 \mathrm{~s}$ and weighed.

2.1.2. Part 2: Acute Postprandial Effect of Ingestion of Breads Matched for Mass. Eleven overweight or obese males completed part 2, 9 of whom also completed part 1. The same test 
TABLE 2: Nutrient composition of the test breads delivering a consistent portion size (part 2) ${ }^{1}$.

\begin{tabular}{lccccc}
\hline & 11-grain & $\begin{array}{c}\text { Sprouted- } \\
\text { grain }\end{array}$ & Sourdough & 12-grain & White \\
\hline $\begin{array}{l}\text { Total } \\
\text { bread (g) }\end{array}$ & 107.3 & 107.3 & 107.3 & 107.3 & 107.3 \\
$\begin{array}{l}\text { Available } \\
\text { CHO (g) }\end{array}$ & 35.5 & 34.0 & 50.0 & 43.8 & 48.6 \\
$\begin{array}{l}\text { Energy } \\
\text { (kcal) }\end{array}$ & 227.4 & 229.6 & 277.9 & 278.9 & 266.0 \\
$\begin{array}{l}\text { Starch (g) } \\
\text { Total } \\
\text { sugars (g) }\end{array}$ & 31.2 & 31.6 & 45.4 & 37.3 & 42.3 \\
$\begin{array}{l}\text { Soluble } \\
\text { fiber (g) }\end{array}$ & 0.6 & 0.4 & 0.3 & 0.9 & 0.3 \\
$\begin{array}{l}\text { Insoluble } \\
\text { fiber (g) }\end{array}$ & 8.4 & 7.8 & 4.9 & 8.6 & 4.5 \\
$\begin{array}{l}\text { Dietary } \\
\text { fiber (g) }\end{array}$ & 9.1 & 8.2 & 5.2 & 9.6 & 4.8 \\
$\begin{array}{l}\text { Protein (g) } \\
\text { Fat (g) }\end{array}$ & 12.0 & 15.2 & 9.0 & 11.0 & 9.5 \\
\hline
\end{tabular}

${ }^{1}$ Test breads were analyzed by Laboratories of Canada Incorporated (ILC) in Tillsonburg, ON.

${ }^{2}$ Available $\mathrm{CHO}$ was calculated using this formula: starch + total sugar.

breads studied in part 1 were prepared to provide a consistent portion of $107 \mathrm{~g}$. This volume was selected as it allowed for a comparison between parts 1 and 2 for the ingestion of the same quantity of the sourdough bread. This resulted in portions of $35,34,50,43$, and $48 \mathrm{~g}$ of available $\mathrm{CHO}$ for 11grain, sprouted-grain, sourdough white, 12 -grain, and white bread, respectively (Table 2).

2.2. Blood Collection, Biochemical and Dietary Analysis. For analysis of blood glucose, blood samples were collected at all time points into vacutainers containing 72 USP units sodium heparin, immediately put on ice, and subsequently analyzed using a semiautomatic glucose analyzer (YSI 2300, Yellow Springs, OH, USA). For analysis of serum insulin, blood samples were collected at all time points into vacutainers without anticoagulants and centrifuged $(1341 \times \mathrm{g}$ for $10 \mathrm{~min}$ at $4^{\circ} \mathrm{C}$ ). Serum supernatant was aliquoted and frozen at $-20^{\circ} \mathrm{C}$ until analysis using a solid phase ${ }^{125} \mathrm{I}$ radioimmunoassay (Coat-A-Count, Diagnostic Products Corporation, CA, USA) with an intra- and interassay variability of $5.2 \%$ and $7.3 \%$, respectively.

For analysis of the incretin hormones, blood samples were collected at all time points into ice-chilled tubes containing $10.8 \mathrm{mg} \mathrm{K} \mathrm{K}_{2}$ EDTA, $1824 \mathrm{KIU}$ aprotinin, and 10 $\mu \mathrm{L} / \mathrm{mL}$ blood dipeptidyl peptidase- 4 inhibitor. Following centrifugation $\left(1000 \times \mathrm{g}\right.$ for $15 \mathrm{~min}$ at $\left.4^{\circ} \mathrm{C}\right)$, plasma was separated and stored at $-80^{\circ} \mathrm{C}$ until analysis. Plasma GIP total concentrations were measured using a Human GIP (Total) ELISA kit (Linco Research Inc., St Charles, USA) with $100 \%$ crossreactivity to human intact GIP, GIP (142 ), and the N-terminally truncated metabolite, GIP (3$42)$. Intra- and interassay variability for GIP were $6.5 \%$ and 3.4\%, respectively. Plasma GLP-1 total concentrations were measured by GLP-1 total RIA kit (Linco Research Inc., St Charles, USA) after extraction with $70 \%$ ethanol. The antibody used in this kit binds specifically with C-terminal portion of GLP-1, both amidated and nonamidated forms. Intra- and interassay variations for GLP- 1 were $4.0 \%$ and $9.9 \%$, respectively.

Food record data were analyzed for energy, macronutrients, cholesterol, and dietary fiber by using ESHA Food Processor program (version 9.5, Salem, OR, USA) and averaged across each 3-day food record.

2.3. Calculations and Statistical Analysis. Incremental area under the curve (AUC) was determined for blood glucose, serum insulin, plasma GIP, and GLP-1 (GraphPad Prism, version 3.02, San Diego, CA, USA). Prism computes the incremental area under the curve by using the trapezoid rule. Time point -15 was used as the baseline, and values below the baseline were considered to be negative peaks. Insulin Sensitivity Index (ISI) was calculated using the method described by Matsuda and DeFronzo [21].

All statistical analyses were performed using the Statistical Analysis System (SAS Institute Inc., version 9.1 Cary, NC, USA). Univariate analysis was used to examine the distribution of each variable, and logarithmic transformations were applied to data that was not normally distributed (specific variables are identified in data tables). Significance $(P<$ 0.05 ) was tested by two-factor repeated measure analysis of variance (ANOVA) using a mixed model (treatment: fixed effect and subject: random effect) followed by the Tukey's test for multiple comparisons. Results are presented as mean \pm SEM.

\section{Results}

\subsection{Part 1: Acute Postprandial Effect of Ingestion Breads Matched for Available $\mathrm{CHO}$}

3.1.1. Subjects. Twelve subjects (age: $54.9 \pm 2.0$ y, BMI: $29.1 \pm$ $1.1 \mathrm{~kg} / \mathrm{m}^{2}$, fasting blood glucose: $4.5 \pm 0.1 \mathrm{mmol} / \mathrm{L}$, fasting serum insulin: $50.8 \pm 4.8 \mathrm{pmol} / \mathrm{L}$ ) completed part 1 of the study.

3.1.2. Blood Glucose. Significant overall treatment effects were found in glucose responses to the breads (Figure 1). Sprouted-grain bread was significantly lower than 11-grain $(P<0.009)$, sourdough $(P<0.001)$, and white $(P<0.006)$ breads. Furthermore, 12 -grain bread was significantly lower than 11-grain $(P<0.04)$ and sourdough $(P<0.003)$ breads. Similarly, glucose incremental AUC for sproutedgrain bread was significantly lower than 11-grain $(P<$ $0.007)$, sourdough $(P<0.004)$, and white $(P<0.05)$ breads (Table 3). Furthermore, glucose incremental AUC for 12grain bread was significantly lower than 11 -grain $(P<0.01)$ and sourdough $(P<0.009)$ breads (Table 3$)$.

3.1.3. Serum Insulin and Insulin Sensitivity. Significant overall treatment effects were found in insulin responses to the 
TABLE 3: Incremental area under the curve for blood glucose, serum insulin, plasma GIP and GLP-1 after ingestion of $50 \mathrm{~g}$ available CHO of the test breads for $180 \mathrm{~min}(\text { part } 1)^{1,2}$.

\begin{tabular}{|c|c|c|c|c|c|}
\hline & 11-grain & Sprouted-grain & Sourdough & 12-grain & White \\
\hline Glucose $(\mathrm{mM} / \mathrm{L} \cdot \mathrm{min})$ & $0.64^{\mathrm{a}} \pm 0.04$ & $0.22^{\mathrm{b}} \pm 0.17$ & $0.66^{\mathrm{a}} \pm 0.16$ & $0.26^{\mathrm{bc}} \pm 11.0$ & $0.51^{\mathrm{ac}} \pm 0.17$ \\
\hline Insulin $(\mathrm{nM} / \mathrm{L} * 180 \mathrm{~min})$ & $31.6^{\mathrm{a}} \pm 6$ & $30.4^{\mathrm{a}} \pm 5$ & $21.4^{\mathrm{b}} \pm 3.3$ & $25.9^{\mathrm{ab}} \pm 6.8$ & $24.1^{\mathrm{b}} \pm 4.5$ \\
\hline $\mathrm{GIP}(\mathrm{nM} / \mathrm{L} * 180 \mathrm{~min})$ & $3.2 \pm 0.4$ & $3.7 \pm 0.3$ & $3.6 \pm 0.4$ & $3.6 \pm 0.4$ & $3.3 \pm 0.2$ \\
\hline $\mathrm{GLP}-1^{3}(\mathrm{nM} / \mathrm{L} * 180 \mathrm{~min})$ & $0.58 \pm 0.23$ & $0.57 \pm 0.32$ & $-0.04 \pm 0.16$ & $0.38 \pm 0.2$ & $0.41 \pm 0.31$ \\
\hline
\end{tabular}

${ }^{1}$ All values are mean $( \pm$ SEM $) ;(n=12)$ except for GLP-1 $(n=11)$ because of technical problems.

${ }^{2}$ Mean values within a row with different superscript letters were significantly different $(P<0.05)$.

${ }^{3}$ Data was log-transformed prior to statistical analysis and is presented as the geometric mean \pm SEM.

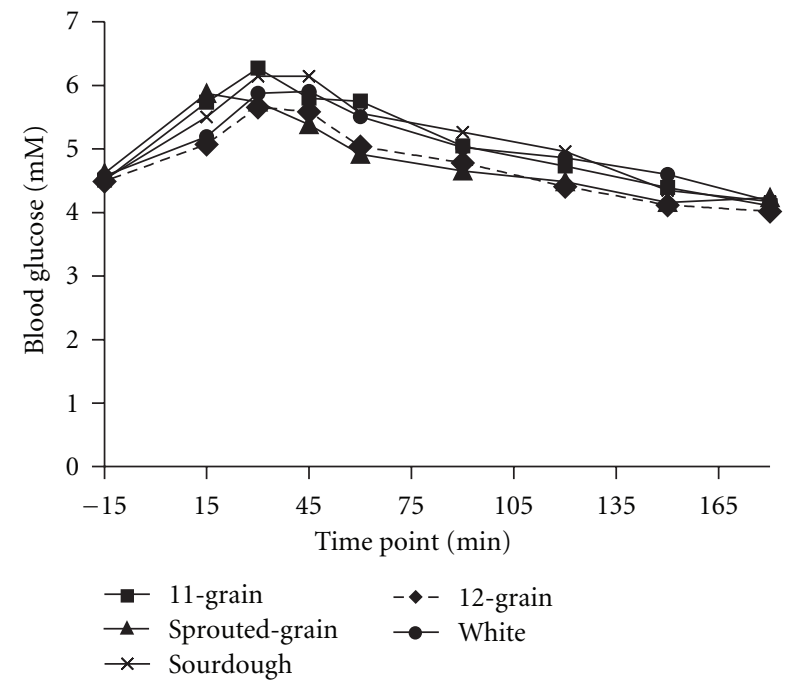

Figure 1: Fasting and postprandial glucose responses to the ingestion of $50 \mathrm{~g}$ available carbohydrate of the test breads. Data are means. Standard errors are not included for clarity, $n=12$. Test bread was ingested after collection of fasting blood sample at time point $-15 \mathrm{~min}$. Significant overall treatment effects were found in glucose responses to the breads (Sprouted-grain bread was lower than 11-grain $(P<0.009)$, sourdough $(P<0.001)$, and white $(P<0.006)$ breads $)$. Twelve-grain bread was lower than 11-grain $(P<0.04)$ and sourdough $(P<0.003)$ breads $)$.

breads with 11-grain bread being higher than sourdough $(P<0.005)$ and white $(P<0.03)$ breads (Figure 2$)$. Furthermore, insulin incremental AUC for 11-grain and sprouted-grain breads was significantly $(P<0.05)$ greater than sourdough and white breads (Table 3 ). ISI was not significantly different among the breads (data not shown).

3.1.4. Plasma GIP and GLP-1. Despite the difference in insulin responses, there was no significant overall treatment effect in GIP responses to the breads (data not shown). Similarly, bread treatment did not significantly affect GIP incremental AUC (Table 3). The significant differences in overall GLP-1 response to the breads did not correspond with those for insulin. The GLP-1 response to sourdough bread was lower than 11 -grain $(P<0.0001)$, sprouted-grain $(P<0.0001)$, and white $(P<0.02)$ breads. Additionally, the GLP-1 response to 11-grain bread was greater than 12-grain

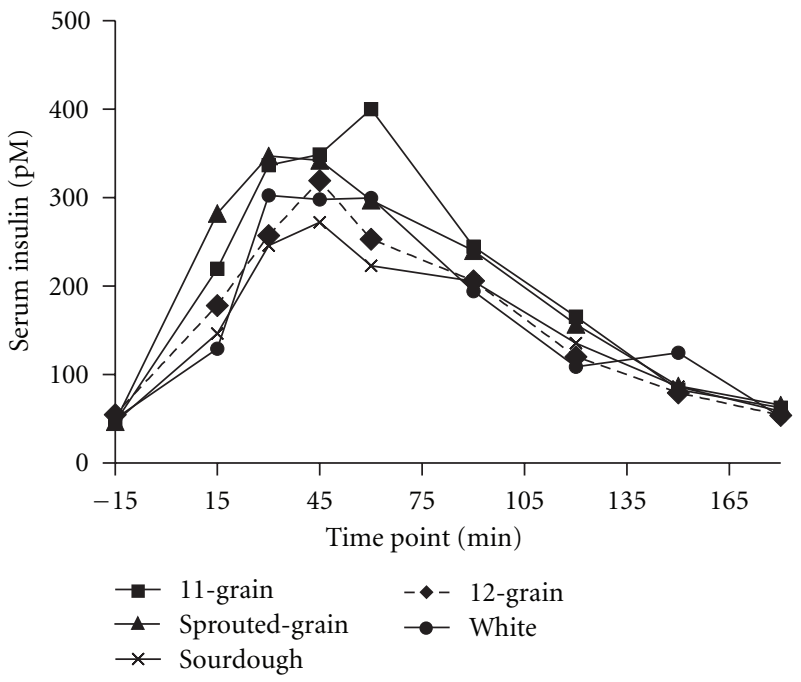

FIGURE 2: Fasting and postprandial insulin response to the ingestion of $50 \mathrm{~g}$ available carbohydrate of the test breads. Data are means. Standard errors are not included for clarity, $n=12$. Test bread was ingested after collection of fasting blood sample at time point $-15 \mathrm{~min}$. Significant overall treatment effects were identified (11grain bread was greater than sourdough $(P<0.005)$ and white $(P<0.03)$ breads $)$.

$(P<0.03)$ and white $(P<0.03)$ breads, while the GLP-1 response to sprouted-grain bread was greater than 12-grain $(P<0.009)$ and white $(P<0.05)$ breads (Figure 3$)$. Despite these differences, bread treatment did not significantly affect GLP-1 incremental AUC (Table 3).

\subsection{Part 2: Acute Postprandial Effect of Ingestion of Breads Matched for Mass}

3.2.1. Subjects. Eleven subjects (age: $53.9 \pm 1.7$ y, BMI: $28.6 \pm$ $0.7 \mathrm{~kg} / \mathrm{m}^{2}$, fasting glucose: $4.6 \pm 0.1 \mathrm{mmol} / \mathrm{L}$, fasting insulin: $40.6 \pm 5.7 \mathrm{pmol} / \mathrm{L}$ ) completed part 2 of the study.

3.2.2. Blood Glucose. Although there were no significant overall treatment effects in glucose responses to the breads, glucose incremental AUC for sourdough bread was significantly greater than 11 -grain $(P<0.002)$, sprouted-grain $(P<0.01)$, 12-grain $(P<0.001)$, and white $(P<0.04)$ breads (Table 4). 
TABLE 4: Incremental area under the curve for blood glucose, serum insulin, plasma GIP and GLP-1 responses to the ingestion of set amount of the test breads for $180 \mathrm{~min}$ (part 2) . $^{1,2}$.

\begin{tabular}{lccccc}
\hline & 11-grain & Sprouted-grain & Sourdough & 12-grain & White \\
\hline Glucose $(\mathrm{mM} / \mathrm{L} \cdot \min )$ & $0.31^{\mathrm{a}} \pm 0.12$ & $0.17^{\mathrm{a}} \pm 0.15$ & $0.72^{\mathrm{b}} \pm 0.19$ & $0.41^{\mathrm{a}} \pm 0.11$ & $0.46^{\mathrm{a}} \pm 0.14$ \\
Insulin $(\mathrm{nM} / \mathrm{L} * 180 \mathrm{~min})$ & $16.2^{\mathrm{ac}} \pm 2.1$ & $12.7^{\mathrm{ac}} \pm 1.9$ & $21.5^{\mathrm{b}} \pm 2.7$ & $16.8^{\mathrm{a}} \pm 2.4$ & $18.1^{\mathrm{bc}} \pm 3.4$ \\
$\mathrm{GIP}(\mathrm{nM} / \mathrm{L} * 180 \mathrm{~min})$ & $2.7^{\mathrm{a}} \pm 0.3$ & $3.1^{\mathrm{ab}} \pm 0.3$ & $3.5^{\mathrm{bc}} \pm 0.3$ & $3.3^{\mathrm{ac}} \pm 0.4$ & $4.0^{\mathrm{b}} \pm 0.7$ \\
$\mathrm{GLP}-1^{3}(\mathrm{pM} / \mathrm{L} * 180 \mathrm{~min})$ & $0.48^{\mathrm{ab}} \pm 0.2$ & $0.83^{\mathrm{a}} \pm 0.3$ & $-0.05^{\mathrm{b}} \pm 0.1$ & $-0.19^{\mathrm{b}} \pm 0.5$ & $0.07^{\mathrm{ab}} \pm 0.3$ \\
\hline
\end{tabular}

${ }^{1}$ All values are mean $( \pm$ SEM $) ;(n=11)$ except for GLP-1 $(n=10)$ because of technical problems.

${ }^{2}$ Mean values within a row with different superscript letters were significantly different $(P<0.05)$.

${ }^{3}$ Data was log transformed prior to statistical analysis and is presented as the geometric mean \pm SEM.

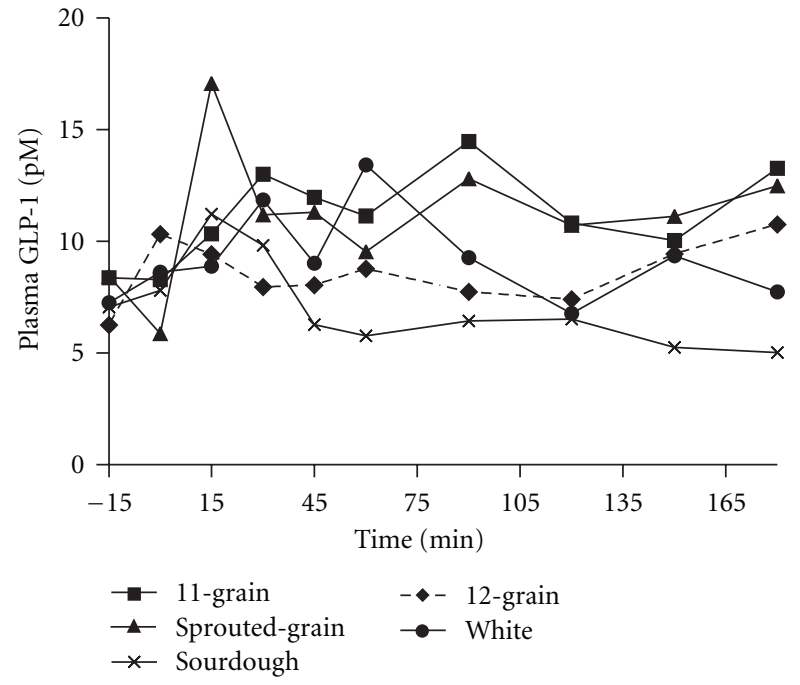

FIGURE 3: Fasting and postprandial GLP-1 responses to the ingestion of $50 \mathrm{~g}$ available carbohydrate of the test breads. Data are means. Standard errors are not included for clarity, $n=11$. Test bread was ingested after collection of fasting blood sample at time point $-15 \mathrm{~min}$. Significant overall treatment effects were found (sourdough bread was lower than 11-grain $(P<0.0001)$, sproutedgrain $(P<0.0001)$, and white $(P<0.02)$ breads. 11 -grain bread was greater than 12 -grain $(P<0.03)$ and white $(P<0.03)$ breads. Sprouted-grain bread was greater than 12 -grain $(P<0.009)$ and white $(P<0.05)$ breads $)$.

3.2.3. Serum Insulin and Insulin Sensitivity. Significant overall treatment effects were found in insulin responses to the breads with sprouted-grain being lower than 12-grain $(P<0.03)$ bread and 12-grain bread being lower than sourdough $(P<0.001)$ and white $(P<0.001)$ breads (Figure 4). Insulin incremental AUC for 11-grain $(P<0.03)$, sprouted-grain $(P<0.05)$, and 12 -grain $(P<0.0007)$ breads was significantly lower than sourdough bread. In addition, insulin incremental AUC for 12-grain was lower than white bread $(P<0.03)$ (Table 4$)$. ISI was not significantly different among the breads (data not shown).

3.2.4. Plasma GIP and GLP-1. As in part 1, incretin responses did not correspond with the postprandial insulin response. Overall GIP response to 11-grain was lower than sourdough bread $(P<0.008)$ (Figure 5). GIP incremental AUC for 11grain bread was significantly lower than sourdough $(P<$

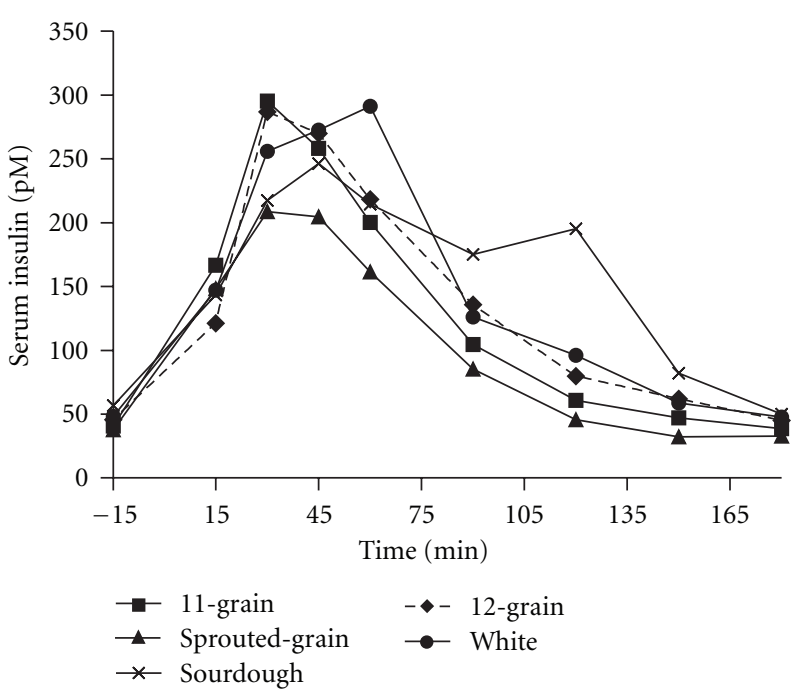

FIGURE 4: Fasting and postprandial insulin responses to the ingestion of a consistent amount of the test breads. Test bread was ingested after collection of fasting blood sample at time point $-15 \mathrm{~min}$. Data are means. Standard errors are not included for clarity, $n=11$. Significant overall treatment effects were found in insulin response to the breads (sprouted-grain bread was lower than 12 -grain $(P<0.03)$ bread, and 12 -grain bread was lower than sourdough $(P<0.001)$ and white $(P<0.001)$ breads $)$.

$0.03)$ and white $(P<0.001)$ breads (Table 4$)$. Despite the modest $(4.8 \mathrm{~g})$ difference in the available $\mathrm{CHO}$ consumed, GIP incremental AUC for 12-grain was lower than white bread $(P<0.03)$ (Table 4$)$.

Similarly, GLP-1 response did not relate to the amount of available $\mathrm{CHO}$ consumed as the overall GLP-1 response to sprouted-grain bread was significantly greater than 11grain $(P<0.008)$, sourdough $(P<0.001)$, 12-grain $(P<0.04)$, and white $(P<0.04)$ breads (Figure 6$)$. GLP-1 incremental AUC for sprouted-grain was significantly greater than sourdough $(P<0.05)$ and 12 -grain $(P<0.01)$ breads (Table 4).

\section{Discussion}

The purpose of the current study was to determine the acute effects of breads of variable carbohydrate composition on postprandial glucose, insulin, and incretin responses in sedentary, overweight/obese males as this population 


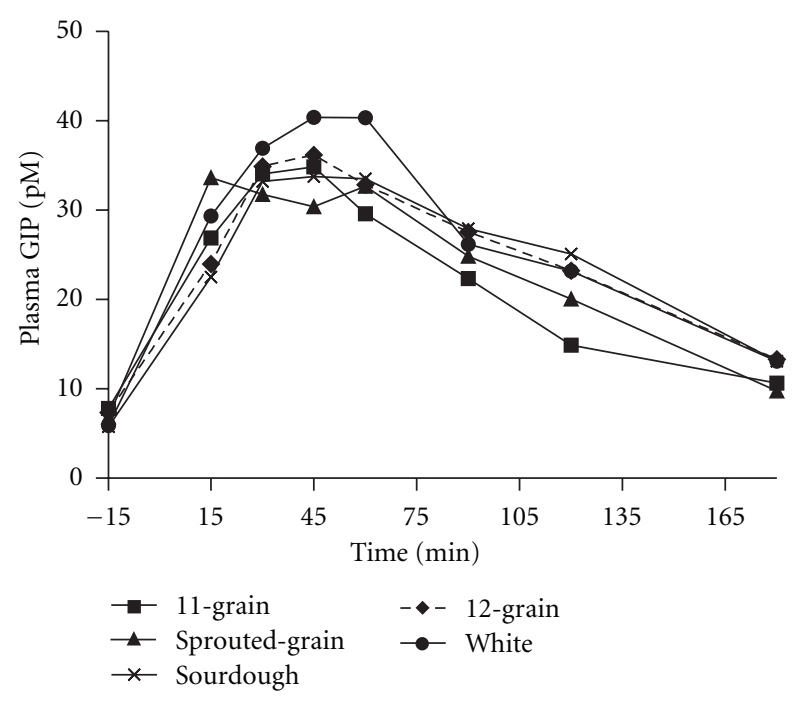

FIGURE 5: Fasting and postprandial GIP responses to the ingestion of a consistent amount of the test breads. Data are means. Standard errors are not included for clarity, $n=11$. Test bread was ingested after collection of fasting blood sample at time point $-15 \mathrm{~min}$. A significant overall treatment effect was found (11-grain bread was lower than sourdough $(P<0.008)$ bread $)$.

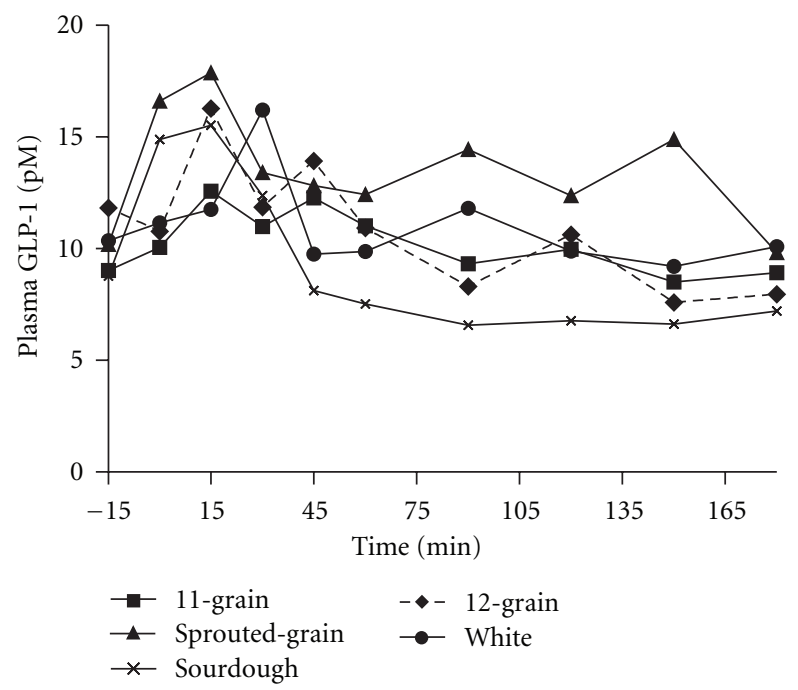

Figure 6: Fasting and postprandial GLP-1 responses to the ingestion of a consistent amount of the test breads. Data are means. Standard errors are not included for clarity, $n=10$. Test bread was ingested after collection of fasting blood sample at time point $-15 \mathrm{~min}$. Significant overall treatment effects were found (sprouted-grain bread was greater than 11-grain $(P<0.008)$, sourdough $(P<0.001)$, 12-grain $(P<0.04)$, and white $(P<0.04)$ breads).

represents a group that are at increased risk for T2D. We hypothesised that the sprouted-grain, whole-grain, and sourdough breads would lower the postprandial metabolic responses, in comparison to white bread, in both parts 1 and 2 of the study. The nature of the subjects and the testing of commercial breads given either in portions based on available $\mathrm{CHO}$ or volume are limitations to interpreting the data, but they also are a strength as the findings are very applicable to society. The key findings were that the sprouted grain bread reduced the glycemic responses in both parts of the study and also that generally the whole-grain breads did not have what could be interpreted as beneficial, metabolic responses. While some differences were observed in the incretin hormones, these did not correspond to the insulin responses.

When $50 \mathrm{~g}$ of available $\mathrm{CHO}$ was ingested (part 1), the glucose response (overall and incremental AUC) to sproutedgrain bread was significantly less than 11-grain, sourdough, and white breads. Additionally, the glucose response (overall and incremental AUC) for 12-grain bread was significantly lower than sourdough and 11-grain breads. The favourable glucose responses to the sprouted-grain and 12-grain breads support our hypothesis. Greater fiber content in sproutedgrain and 12-grain breads (Table 1) may explain the lowered glycemia following their ingestion compared to white and sourdough breads. Dietary fiber is reported to attenuate glycemic response through its physical action in the gut which lowers the rate of $\mathrm{CHO}$ digestion and absorption $[11,12,21-23]$. However, the glucose-lowering effect of cereal fiber has been attributed primarily to soluble fiber $[12,22,24]$, and in the present study, the fiber content of the sprouted-grain and 12-grain breads was predominantly insoluble fiber, suggesting that soluble fiber may not be the only component responsible for improving glycemia. Other nutrients and components in the sprouted-grain and 12grain breads may also have positive health-related effects. It has been suggested that the sprouting treatment of cereal grains increases the content and availability of vitamins, minerals, and antioxidants [19], and whole-grains are known to contain higher amounts of vitamins, minerals, antioxidants, and phytochemicals. The presence of micronutrients such as magnesium, vitamin E, antioxidants, phenolic compounds, and phytoestrogens may act synergistically to lower glycemia $[6-9,25,26]$.

The lack of significant difference in postprandial glucose response between the 11-grain and white bread was unexpected. It should be noted that there are several factors influencing the metabolic responses to breads including the flour particle size, kneading protocol, leavening process, and baking procedure [27-31], but we are currently unable to identify which specific factor may have accounted for the findings in the present study. A strength of this study is its applicability due to the use of commercially prepared breads, but this also presents a limitation as detailed information regarding ingredients (i.e., the grain/flour structure and proportion contribution to each bread) and processing techniques are not available. Furthermore, although we accept that sample size may be another limitation, our results strongly suggest that there are no acute metabolic differences among the other breads. However, this does not mean there are no benefits in consuming these breads rather that any of the benefits are not obvious within the few hours that we studied. In fact, large epidemiological studies show an inverse relationship with whole grain intake and risk of obesity, diabetes, and cardiovascular disease. A large study 
examining almost 43000 people for up to 12 years found that a diet high in whole grains was inversely associated with type 2 diabetes risk [5]. Although the physiological mechanisms remain unclear, the postprandial response to dietary fiber remains a promising mediator of improved health. Conversely, a small randomized crossover study with 30 subjects by Andersson and colleagues [32] aligns with our results suggesting a lack of a favorable postprandial metabolic response to whole grain when compared to refined meals in those who are healthy and slightly overweight. Overall, there is paucity of information on the metabolic responses to breads of varying carbohydrate in overweight and obese men, and investigation with larger sample sizes is warranted to better understand the biological mediators of glycemic control.

While it is possible that any positive effect of the 11-grain bread would be apparent only after a chronic intervention, our findings clearly highlight that whole-grain breads are not the same. Eleven-grain bread was prepared with sourdough culture and contained high amount of fiber and did not improve glycemia; this finding suggests that one cannot generalize across whole-grain products, and the metabolic responses to whole-grains are different for each recipe.

The insulin results did not support our hypothesis. When matched for available $\mathrm{CHO}$, insulin incremental AUCs for 11-grain and sprouted-grain breads were greater than sourdough and white breads (Table 3 ). This is consistent with the glucose data for sprouted-grain and sourdough breads, but does not explain the glucose result for 11-grain bread, suggesting that glycemia does not always predict insulinemia. In the present study, acute ingestion of $50 \mathrm{~g}$ available $\mathrm{CHO}$ from whole-grain and sprouted-grain breads did not improve insulinemia or insulin sensitivity (as assessed by calculation of ISI) compared to white bread. Limited literature is available on acute intervention and the results from epidemiologic $[4,5,7]$ and chronic interventional $[9,10]$ studies suggest that any positive effect of whole-grain food intake on insulinemia and insulin sensitivity is only apparent after a chronic intervention. These findings may help explain the lack of positive effect of acute ingestion of whole-grain breads on insulinemia and insulin sensitivity in our study.

It should be noted that the magnitude of the glucose and insulin (Tables 3 and 4) responses to the sourdough bread was similar in parts 1 and 2 of the study, respectively, and that these data are consistent with those reported previously from our laboratory [18]. While we previously showed that sourdough bread resulted in a more favourable postprandial response compared with whole-wheat bread [18], the breads were all prepared in the laboratory. In the present study, the comparison was with whole-grain (not whole-wheat) breads that were commercially prepared. In the former investigation [18], the breads were all administered to control for available $\mathrm{CHO}$ and thus subjects ingested different amounts of breads. In part 2 of the current study, matching the treatments for volume of bread consumed resulted in a large difference in available $\mathrm{CHO}$ content among the breads. The lower glucose and insulin incremental AUCs for the whole-grain breads compared to those of sourdough bread can be attributed to the lower available $\mathrm{CHO}$ and greater dietary fiber content of the whole-grain treatments.

Incretins are potent insulin-releasing hormones that play an important role in glucose homeostasis. Previously we observed that sourdough bread resulted in lower GLP-1 response [18]. In part 1 of the present study, GIP responses to the ingestion of $50 \mathrm{~g}$ available $\mathrm{CHO}$ of the breads did not differ significantly among the test breads. However, in part 2 , ingestion of equal amounts of the test breads resulted in significantly lower GIP incremental AUC for 11-grain and 12 -grain breads compared to white breads, a result that may be attributed to the lower available $\mathrm{CHO}$ content of these breads. However, the GIP response to sprouted-grain bread, with the lowest available $\mathrm{CHO}$ content, was not lower than those to white bread. In both parts 1 and 2 , the insulin responses did not appear to follow that of the incretins. These findings suggest that postprandial responses for different whole-grain breads are complex and cannot be explained only by the available $\mathrm{CHO}$ content.

Consistent with our previous study [18], in part 1 of the present study, overall GLP-1 response to sourdough bread was significantly lower than 11-grain, sprouted-grain, and white breads. Consistently, insulin response to sourdough bread in part 1 was significantly lower than 11-grain and sprouted-grain breads. Bakhoj et al. [33] reported lowered postprandial GIP responses to the ingestion of Einkorn honey-salt leavened and whole-grain breads compared to the conventional yeast bread and proposed that this was due to an increased level of organic acids (based on reduction of the $\mathrm{pH}$ in the dough). Dietary fiber has also been shown to increase GLP-1 secretion in rats [34] and dogs [35]. A study by Massimino et al. [35] found that highly fermentable dietary fibers were more potent stimulators of GLP-1 secretion compared to low fermentable fibers. Given that the fermentable, insoluble fibre content was greatest in the sprouted-grain and lowest in the sourdough bread, it is reasonable to speculate that the GLP-1 response observed in the present study may in part be influenced by insoluble fiber content of the breads. Lastly, it is important to note that a more refined study of incretin dynamics in an animal model may better characterize the transient postprandial nature of these peptides taking into account their relatively short halflives. In our study, however, we were ethically constrained and only able to draw a certain number of samples that were mixed venous in nature thus why we opted to examine the incretin response as incremental AUC.

Overall, the results of the current investigation suggest that glucose metabolism is complex and multifactorial. The simple model of glucose stimulated insulin secretion, and incretins regulating postprandial insulin release does not always apply. Additionally, GIP and GLP-1 do not respond in a similar manner with respect to the $\mathrm{CHO}$ ingested. In our previous [18] and present studies, we showed that the nature of the bread consumed has an impact on glucose, insulin, and incretin responses, but the mechanism is complex and requires further investigation.

To our knowledge, this is the first study to compare postprandial responses to ingestion of various breads delivering an identical amount of available $\mathrm{CHO}$ (thus different 
masses) with the postprandial effect of ingestion of a fixed portion size (thus same volume, but different amounts of available $\mathrm{CHO}$ ) of the same breads in overweight/obese men. It appears that bread volume and fiber content may play a role but are not the dominant factors in determining the metabolic responses to the breads, as in part 2 of the study, 11-grain, sprouted-grain, and 12-grain breads, with similar volume and fiber content, induced different results in almost every measure. These results suggest that the nature of the ingredients is an important factor influencing the metabolic responses to the breads. Lack of difference between 11-grain and white breads was unexpected but it may be that any positive impact of 11-grain on glucose metabolism only occurs after a chronic dietary intervention.

\section{Conclusion}

While the study is limited due to its applied nature (i.e., employing commercial breads and a somewhat heterogeneous subject set), this is also a strength in terms of applying the findings to the lifestyle of society. Despite the variation that these factors produced, the investigation demonstrated that sprouted grain bread attenuated the glycemic response when both portion size and available carbohydrate were controlled for and that, generally, the whole-grain breads did not have what could be interpreted as beneficial, metabolic responses.

\section{Disclosure}

At the time of research completion, all authors were affiliated with the Department of Human Health and Nutritional Sciences, University of Guelph, Canada.

\section{Acknowledgments}

The authors wish to thank Stone-mill Bakehouse for generously donating the 11-grain and sprouted-grain breads and Hayhoe Mills Ltd. for providing the flour for the sourdough bread. Special thanks to Premila Sathasivam and Mehrnoosh Kashani for their excellent technical assistance. Financial support from the Food Research Program of the Ontario Ministry of Agriculture, Food and Rural Affairs is greatly appreciated. This work was also supported by an industrial NSERC scholarship to A. Mofidi sponsored by Stone-Mill Bakehouse, ON, Canada. A. Mofidi assisted with the protocol development, collected, analyzed and interpreted the data, and drafted the paper. Z. M. Ferraro assisted with the study implementation, data collection, paper preparation, and revision. K. A. Stewart assisted with the study implementation and data collection. H. M. F. Tulk assisted with the protocol development, study implementation, and data collection. L. E. Robinson contributed to the study design, the protocol development, and paper revision. A. M. Duncan contributed to the study design, protocol development, statistical analysis, and paper revision. T. E. Graham designed the study, supervised the research, directed the data analysis and interpretation, and provided significant assistance during paper preparation. None of the authors have conflict of interests. All authors read and approved the final paper. This study was supported by a grant from the Food Research Program of the Ontario Ministry of Agriculture, Food and Rural Affairs (OMAFRA) and a NSERC Industrial scholarship to A. Mofidi sponsored by Stone-Mill Bakehouse, ON, Canada.

\section{References}

[1] E. Bonora and M. Muggeo, "Postprandial blood glucose as a risk factor for cardiovascular disease in Type II diabetes: the epidemiological evidence," Diabetologia, vol. 44, no. 12, pp. 2107-2114, 2001.

[2] K. M. Behall, D. J. Scholfield, and J. Hallfrisch, "The effect of particle size of whole-grain flour on plasma glucose, insulin, glucagon and thyroid-stimulating hormone in humans," Journal of the American College of Nutrition, vol. 18, no. 6, pp. 591597, 1999.

[3] J. P. Bantle, J. Wylie-Rosett, A. L. Albright et al., "Nutrition recommendations and interventions for diabetes-2006: a position statement of the American diabetes association," Diabetes Care, vol. 29, no. 9, pp. 2140-2157, 2006.

[4] A. Esmaillzadeh, P. Mirmiran, and F. Azizi, "Whole-grain consumption and the metabolic syndrome: a favorable association in Tehranian adults," European Journal of Clinical Nutrition, vol. 59, no. 3, pp. 353-362, 2005.

[5] T. T. Fung, F. B. Hu, M. A. Pereira et al., "Whole-grain intake and the risk of type 2 diabetes: a prospective study in men," American Journal of Clinical Nutrition, vol. 76, no. 3, pp. 535$540,2002$.

[6] A. D. Liese, A. K. Roach, K. C. Sparks, L. Marquart, R. B. D’Agostino Jr., and E. J. Mayer-Davis, "Whole-grain intake and insulin sensitivity: the insulin resistance atherosclerosis study," American Journal of Clinical Nutrition, vol. 78, no. 5, pp. 965-971, 2003.

[7] N. M. McKeown, J. B. Meigs, S. Liu, P. W. Wilson, and P. F. Jacques, "Whole-grain intake is favorably associated with metabolic risk factors for type 2 diabetes and cardiovascular disease in the framingham offspring study," American Journal of Clinical Nutrition, vol. 76, no. 2, pp. 390-398, 2002.

[8] P. K. Newby, J. Maras, P. Bakun, D. Muller, L. Ferrucci, and K. L. Tucker, "Intake of whole grains, refined grains, and cereal fiber measured with 7-d diet records and associations with risk factors for chronic disease," American Journal of Clinical Nutrition, vol. 86, no. 6, pp. 1745-1753, 2007.

[9] M. A. Pereira, D. R. Jacobs Jr., J. J. Pins et al., "Effect of whole grains on insulin sensitivity in overweight hyperinsulinemic adults," American Journal of Clinical Nutrition, vol. 75, no. 5, pp. 848-855, 2002.

[10] K. Rave, K. Roggen, S. Dellweg, T. Heise, and H. Tom Dieck, "Improvement of insulin resistance after diet with a whole-grain based dietary product: results of a randomized, controlled cross-over study in obese subjects with elevated fasting blood glucose," British Journal of Nutrition, vol. 98, no. 5, pp. 929-936, 2007.

[11] A. C. Nilsson, E. M. Ostman, J. J. Holst, and I. M. E. Bjorck, "Including indigestible carbohydrates in the evening meal of healthy subjects improves glucose tolerance, lowers inflammatory markers, and increases satiety after a subsequent standardized breakfast," Journal of Nutrition, vol. 138, no. 4, pp. 732-739, 2008. 
[12] A. Tabatabai and S. Li, "Dietary fiber and type 2 diabetes," Clinical Excellence for Nurse Practitioners, vol. 4, no. 5, pp. 272276, 2000.

[13] M. O. Weickert, M. Mohlig, C. Schofl et al., "Cereal fiber improves whole-body insulin sensitivity in overweight and obese women," Diabetes Care, vol. 29, no. 4, pp. 775-780, 2006.

[14] R. Burcelin, "The incretins: a link between nutrients and wellbeing," British Journal of Nutrition, vol. 93, supplement 1, pp. S147-S156, 2005.

[15] D. J. Drucker, "The biology of incretin hormones," Cell Metabolism, vol. 3, no. 3, pp. 153-165, 2006.

[16] J. F. Gautier, S. Fetita, E. Sobngwi, and C. Salaun-Martin, "Biological actions of the incretins GIP and GLP-1 and therapeutic perspectives in patients with type 2 diabetes," Diabetes and Metabolism, vol. 31, no. 3, part I, pp. 233-242, 2005.

[17] J. J. Holst and J. Gromada, "Role of incretin hormones in the regulation of insulin secretion in diabetic and nondiabetic humans," American Journal of Physiology, vol. 287, no. 2, pp. E199-E206, 2004.

[18] A. M. Najjar, P. M. Parsons, A. M. Duncan, L. E. Robinson, R. Y. Yada, and T. E. Graham, "The acute impact of ingestion of breads of varying composition on blood glucose, insulin and incretins following first and second meals," British Journal of Nutrition, vol. 101, no. 3, pp. 391-398, 2009.

[19] K. Lorenz, "Cereal sprouts: composition, nutritive value, food applications," Critical Reviews in Food Science and Nutrition, vol. 13, no. 4, pp. 353-385, 1980.

[20] Y. Ito, A. Mizukuchi, M. Kise et al., "Postprandial blood glucose and insulin responses to pre-germinated brown rice in healthy subjects," Journal of Medical Investigation, vol. 52, no. 3-4, pp. 159-164, 2005.

[21] M. Matsuda and R. A. DeFronzo, "Insulin sensitivity indices obtained from oral glucose tolerance testing: comparison with the euglycemic insulin clamp," Diabetes Care, vol. 22, no. 9, pp. 1462-1470, 1999.

[22] M. C. Casiraghi, M. Garsetti, G. Testolin, and F. Brighenti, "Post-prandial responses to cereal products enriched with barley $\beta$-glucan," Journal of the American College of Nutrition, vol. 25, no. 4, pp. 313-320, 2006.

[23] D. J. Jenkins, A. L. Jenkins, and T. M. Wolever, "Fiber and starchy foods: gut function and implications in disease," American Journal of Gastroenterology, vol. 81, no. 10, pp. 920 930, 1986

[24] P. Wursch and F. X. Pi-Sunyer, "The role of viscous soluble fiber in the metabolic control of diabetes: a review with special emphasis on cereals rich in $\beta$-glucan," Diabetes Care, vol. 20, no. 11 , pp. $1774-1780,1997$.

[25] J. Montonen, P. Knekt, R. Jarvinen, A. Aromaa, and A. Reunanen, "Whole-grain and fiber intake and the incidence of type 2 diabetes," American Journal of Clinical Nutrition, vol. 77, no. 3, pp. 622-629, 2003.

[26] K. Kaline, S. R. Bornstein, A. Bergmann, H. Hauner, and P. E. Schwarz, "The importance and effect of dietary fiber in diabetes prevention with particular consideration of whole grain products," Hormone and Metabolic Research, vol. 39, no. 9, pp. 687-693, 2007.

[27] C. Hoebler, A. Karinthi, H. Chiron, M. Champ, and J. L. Barry, "Bioavailability of starch in bread rich in amylose: metabolic responses in healthy subjects and starch structure," European Journal of Clinical Nutrition, vol. 53, no. 5, pp. 360-366, 1999.

[28] J. Holm and I. Bjorck, "Bioavailability of starch in various wheat-based bread products: evaluation of metabolic responses in healthy subjects and rate and extent of in vitro starch digestion," American Journal of Clinical Nutrition, vol. 55, no. 2, pp. 420-429, 1992.

[29] H. Liljeberg, Y. Granfeldt, and I. Bjorck, "Metabolic responses to starch in bread containing intact kernels versus milled flour," European Journal of Clinical Nutrition, vol. 46, no. 8, pp. 561-575, 1992.

[30] S. W. Rizkalla, M. Laromiguiere, M. Champ, F. Bruzzo, J. Boillot, and G. Slama, "Effect of baking process on postprandial metabolic consequences: randomized trials in normal and type 2 diabetic subjects," European Journal of Clinical Nutrition, vol. 61, no. 2, pp. 175-183, 2007.

[31] P. Snow and K. O'Dea, "Factors affecting the rate of hydrolysis of starch in food," American Journal of Clinical Nutrition, vol. 34, no. 12, pp. 2721-2727, 1981.

[32] A. Andersson, S. Tengblad, B. Karlström et al., "Wholegrain foods do not affect insulin sensitivity or markers of lipid peroxidation and inflammation in healthy, moderately overweight subjects," Journal of Nutrition, vol. 137, no. 6, pp. 1401-1407, 2007.

[33] S. Bakhoj, A. Flint, J. J. Holst, and I. Tetens, "Lowel glucosedependent insulinotropic polypeptide (GIP) response but similar glucagon-like peptide 1 (GLP-1), glycaemic, and insulinaemic response to ancient wheat compared to modern wheat depends on processing," European Journal of Clinical Nutrition, vol. 57, no. 10, pp. 1254-1261, 2003.

[34] R. A. Reimer and M. I. Mcburney, "Dietary fiber modulates intestinal proglucagon messenger ribonucleic acid and postprandial secretion of glucagon-like peptide-1 and insulin in rats," Endocrinology, vol. 137, no. 9, pp. 3948-3956, 1996.

[35] S. P. Massimino, M. I. McBurney, C. J. Field et al., "Fermentable dietary fiber increases GLP-1 secretion and improves glucose homeostasis despite increased intestinal glucose transport capacity in healthy dogs," Journal of Nutrition, vol. 128, no. 10, pp. 1786-1793, 1998. 


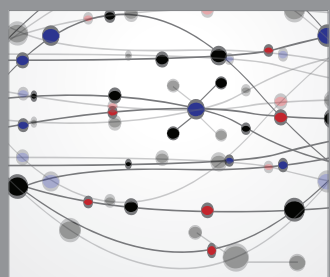

The Scientific World Journal
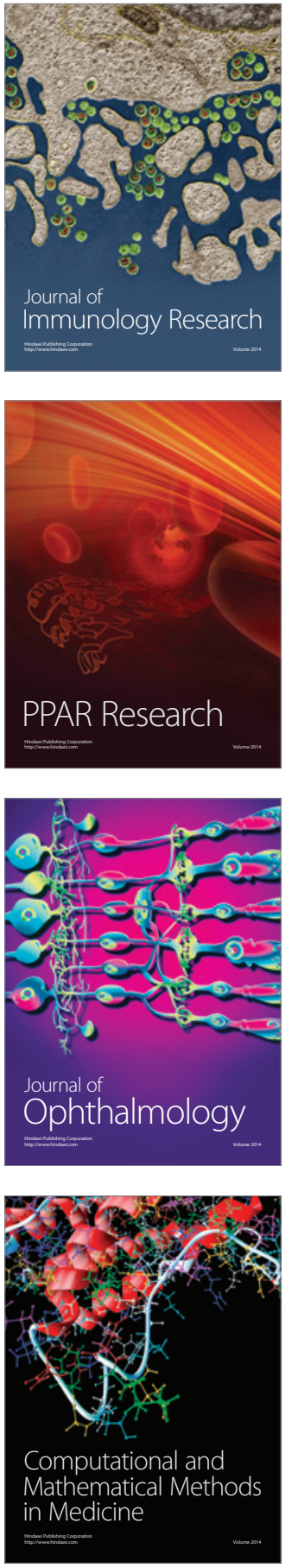

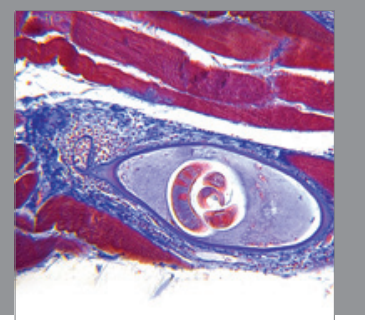

Gastroenterology

Research and Practice
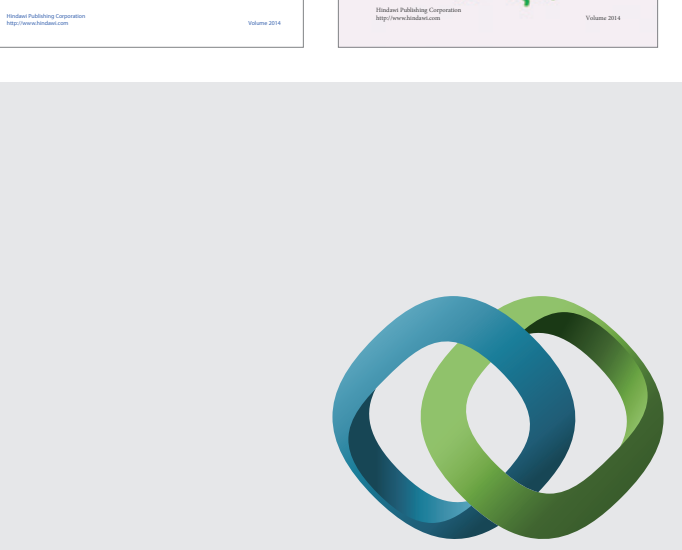

\section{Hindawi}

Submit your manuscripts at

http://www.hindawi.com
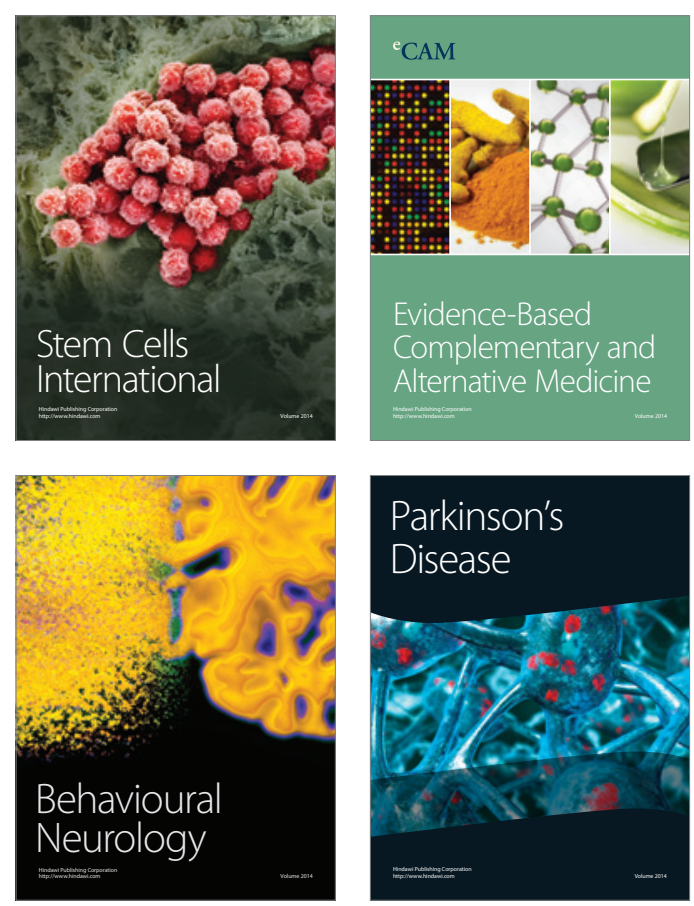

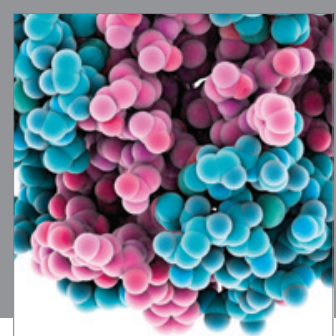

Journal of
Diabetes Research

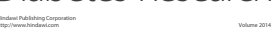

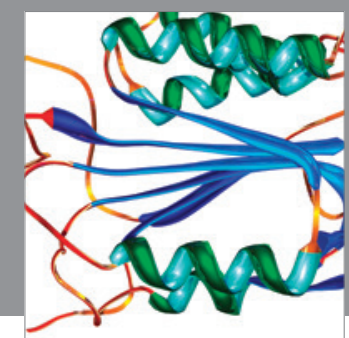

Disease Markers
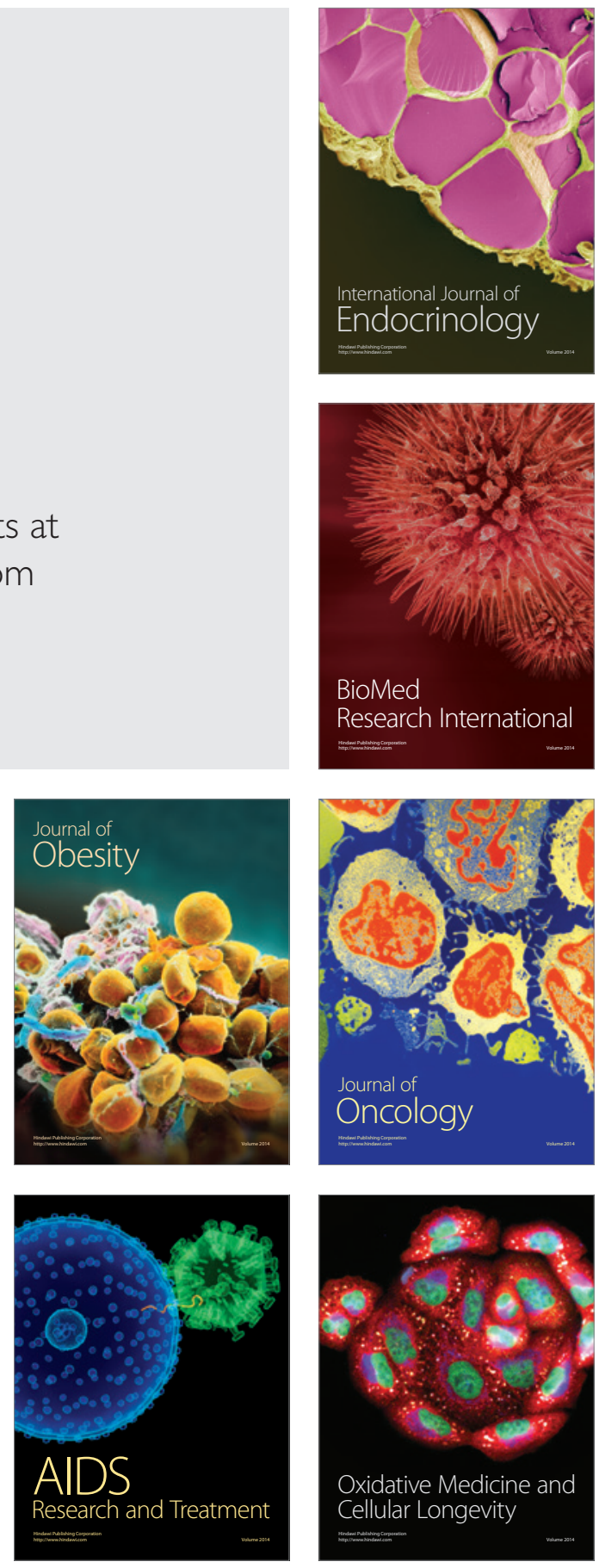